\title{
Erratum to: The Majority of Genetic Variation in Orangutan Personality and Subjective Well-Being is Nonadditive
}

Mark James Adams • James E. King • Alexander Weiss

Published online: 1 August 2012

(C) Springer Science+Business Media, LLC 2012

Erratum to: Behav Genet (2012) 42(4):675-686

DOI 10.1007/s10519-012-9537-y

1. The URL in note \#1 on page 677 is incorrect. The correct URL is <http://extras.springer.com/2011/9781-4614-0175-9>.
2. The value for the nonadditive (dominance) genetic correlation between Dominance and Neuroticism in Table 4 is reported with a number of decimal places inconsistent with the rest of the table. The value should be reported as ".03".

The online version of the original article can be found under doi: 10.1007/s10519-012-9537-y.

M. J. Adams $(\bowtie)$ · A. Weiss

Department of Psychology, School of Philosophy, Psychology and Language Sciences, The University of Edinburgh,

7 George Square, Edinburgh EH8 9JZ, UK

e-mail:m.j.adams-2@sms.ed.ac.uk

M. J. Adams · A. Weiss

Scottish Primate Research Group, Scotland, UK

J. E. King

Department of Psychology, The University of Arizona,

Tucson, AZ, USA 